\title{
Penicillin treatment for gonorrhoea in relation to early syphilis in prostitutes
}

\author{
C S BRADBEER, * R N THIN, * T TAN, $\dagger$ T THIRUMOORTHY $\dagger$ \\ From the *Department of Genitourinary Medicine, St Thomas's Hospital, London, and the $†$ Middle Road \\ Hospital, Singapore
}

SUMMARY A retrospective study of prostitutes in Singapore showed that they had received less antigonorrhoeal treatment with penicillin derivatives during the three month period before early syphilis was diagnosed than in other three month periods when they had not developed syphilis. This suggests that penicillin derivatives in doses sufficient to treat gonorrhoea will abort coincidental early syphilis.

Treating gonorrhoea with antitreponemal drugs is widely thought to abort coincidental early syphilis, but data to support this view appear to be scanty. A prospective study has shown that procaine and benzathine formulations of penicillin in doses as low as 0.6 MIU prevent the development of syphilis when used to treat gonorrhoea in patients who were also sexual contacts of people with syphilis. ${ }^{1}$ The patients had been exposed simultaneously to gonorrhoea and, because of the short incubation period of gonorrhoea, were treated at the very early stages of incubating syphilis. Deliberate treatment of primary syphilis with 5 MIU benzylpenicillin by Hallinger caused transient regression, but clinical or serological relapse, in seven out of eight patients in 11 weeks. ${ }^{2}$

Prostitutes are continually exposed to multiple sexually transmitted diseases. The effect of treatment for gonorrhoea on the incidence of syphilis in this group of patients has not so far been studied. Male and female prostitutes in Singapore, where the prevalence of both diseases is high, are ideal models for such a study. Prostitutes are registered with a clinic and tested every three months for syphilis (by the Venereal Disease Research Laboratory (VDRL) blood test) and every two weeks for gonorrhoea (by culture). During the past eight years various treatment regimens have been used for gonorrhoea. Infection with non-penicillinase producing Neisseria gonorrhoeae (nonPPNG) strains is treated with 4.5 MIU intramuscular procaine penicillin with $1 \mathrm{~g}$ oral probencid. In the late 1970s infection with PPNG strains was treated with

Address for reprints: Dr C S Bradbeer, Department of Genitourinary Medicine, St Thomas's Hospital, Lambeth Palace Road, London SE1 7EH

Accepted for publication 14 April 1987 kanamycin $2 \mathrm{~g}$ alone but, as early syphilis increased at that time, non-allergic patients were also given ampicillin $3.5 \mathrm{~g}$ and probencid $1 \mathrm{~g}$ by mouth. Occasional clinical trials led to the treatment of PPNG infections with spectinomycin or acrosoxacin.

The absence of data on the effect of penicillin on incubating syphilis led us to examine this problem. We formulated a null hypothesis that "single dose antigonococcal penicillin treatment will not affect incubating syphilis, so there will be no difference in the amount of penicillin received by prostitutes who subsequently develop syphilis and those who do not". The maximum incubation period of syphilis is generally accepted as being three months. ${ }^{3}$ If the null hypothesis were true, we would expect prostitutes to have received the same amount of treatment for gonorrhoea in the trimester before they developed syphilis as at other times. There are many variables to be taken into account, and we used prostitutes as their own controls to eliminate some of these variables.

\section{Patients and methods}

The clinic records of prostitutes with a serological diagnosis of secondary syphilis were examined retrospectively to assess the timing of episodes of early syphilis in relation to treatment for gonorrhoea.

For this study, syphilis was diagnosed by a fourfold or more rise in titre in the VDRL test in six months. Gonorrhoea was diagnosed by culture of specimens (from the rectums and cervices of women and the rectums and pharynxes of men) on Thayer-Martin medium in the laboratory as described by Lim et al. ${ }^{4}$ Prostitutes were excluded if the previous VDRL test had been undertaken more than six months before the diagnosis of syphilis or if fewer than three specimens 
for culture for gonococci had been taken in that period.

We noted the number of episodes of gonorrhoea in the timester before the serological diagnosis of syphilis and the treatment given. We recorded the same data for four other trimesters (the three trimesters before the incubation period and the one after) for each prostitute as a comparison. Each trimester was numbered for convenience, as shown in table 1. Treatment for gonorrhoea was with either penicillin derivatives (procaine penicillin or ampicillin) or non-treponemicidal antibiotics (acrosoxacin, kanamycin, or streptomycin).

Statistical comparisons were made by the $\chi^{2}$ test.

\section{Results}

A total of 93 episodes of early syphilis had been detected and treated in 71 patients (60 episodes in 39 male prostitutes and 33 episodes in 32 female prostitutes). The previous VDRL test had been taken within three months of diagnosis in 81 cases and three to six months earlier in the 12 remaining cases:

Table 1 shows the numbers examined and the proportions of them treated with penicillin in each trimester. Of 93 patients examined in the incubation trimester, $12 \%$ (11) had received penicillin compared with a mean of $29 \%(96 / 328)$ of the same patients examined in the other four trimesters.

Table 2 shows the numbers of patients with gonorrhoea and the proportions treated with penicillin in each trimester. Of the 20 with gonorrhoea in the trimester when syphilis was incubating, $11(55 \%)$ were treated with penicillin compared with a mean of $79 \%$ $(96 / 122)$ in the other four trimesters. The timing of the treatment and the titres in the VDRL test in the 11 treated with penicillin did not differ from those in the nine patients receiving non-treponemicidal antibiotics.

Table 1 Penicillin treatment for gonorrhoea in patients who had 93 episodes of concomittant early syphilis: treatment of same patients in trimesters when syphilis did not develop compared with that (trimester 4) when it did

\begin{tabular}{llll}
\hline $\begin{array}{l}\text { Trimesters } \\
\text { (in relation to } \\
\text { diagnosis of } \\
\text { syphilis) }\end{array}$ & $\begin{array}{l}\text { No of } \\
\text { examinations* }\end{array}$ & $\begin{array}{l}\text { No (\%) of } \\
\text { episodes } \\
\text { treated with } \\
\text { penicillin }\end{array}$ & $\begin{array}{l}\text { Comparison } \\
\text { with } \\
\text { trimester 4 }\end{array}$ \\
\hline $\begin{array}{l}\text { 1 } \begin{array}{l}(12-9 \text { months } \\
\text { before) }\end{array} \\
\text { (9-6 months }\end{array}$ & 70 & $26(37)$ & $\mathrm{p}<0.001$ \\
before) & 80 & $26(33)$ & $\mathrm{p}<0.01$ \\
$\begin{array}{l}(6-3 \text { months } \\
\text { before) }\end{array}$ & 91 & $29(32)$ & $\mathrm{p}<0.01$ \\
$\begin{array}{l}(3 \text { months before) } \\
\text { (incubation } \\
\text { period) }\end{array}$ & 93 & $11(12)$ & $\mathrm{NS}$ \\
5 (0-3 months after) & 87 & $15(17)$ & $\mathrm{NS}$ \\
\hline
\end{tabular}

*Examinations of same patients that had 93 episodes of early syphilis.
Table 2 Number of patients with gonorrhoea in each trimester and percentage treated with penicillin

\begin{tabular}{lll}
\hline Trimesters & $\begin{array}{l}\text { No of patients } \\
\text { with gonorrhoea }\end{array}$ & $\begin{array}{l}\text { No (\%) of patients } \\
\text { treated with penicillin }\end{array}$ \\
\hline 1 & 29 & $26(90)$ \\
2 & 33 & $26(79)$ \\
3 & 38 & $29(76)$ \\
4 & 20 & $11(55)$ \\
5 & 22 & $15(68)$ \\
\hline
\end{tabular}

\section{Discussion}

As table 1 shows, there was a significant fall in the percentage of patients with gonorrhoea treated with penicillin in trimester 4 (immediately before the diagnosis of syphilis) compared with the earlier trimesters $(p<0.01$ and $p<0.001)$. This suggests that penicillin and its derivatives when used to treat gonorrhoea will help to abort early syphilis. The null hypothesis was thus disproved. The findings also show that the effects of single dose penicillin in incubating syphilis, which were first noted 16 to 19 years ago, are being maintained.

Eleven prostitutes had evidence of early syphilis after penicillin treatment. This may have been because some acquired syphilis after their treatment for gonorrhoea, some received anti-gonococcal treatment too late for it to abort their syphilis, and in others the disease could already have been aborted and the VDRL test undertaken as the titre was falling.

The figures for gonorrhoea and penicillin treatment for the trimester after the diagnosis of syphilis (trimester 5) show less gonorrhoea than in the other control trimesters. This may be explained in several ways. The routine treatment for early syphilis in Singapore is two injections of 2.4 MIU benzathine penicillin at an interval of one week. This would have given low tissue concentrations of penicillin for about half of trimester 5 and might have provided some protection against new infection with gonorrhoea. The reduction in the number of episodes of gonorrhoea in trimester 4 was presumably due to some incidental change in lifestyle. It is unlikely that such a change, which might simply have been the use of a diaphragm or reduction in the number of clients, would have led to both an increase in syphilis and a reduction in gonorrhoea. The reduced rate of gonococcal infections in trimester 5 could, however, be explained by such a change continuing.

Our results support the policy of adding penicillin to non-treponemicidal treatment for gonorrhoea to assist the control of syphilis in areas where it is very prevalent, although clearly this is not a satisfactory method of treating proved syphilis and should not be used for this purpose. 
Prospective studies should be undertaken to confirm our findings and to assess the effect of benzathine penicillin in preventing gonorrhoea.

\section{References}

1 Schroeter AL, Turner RH, Lucas JB, et al. Therapy for incubating syphilis. JAMA 1971;218:711-3.
2 Hallinger L. Experimental undertreatment of early syphilis with probenicid and penicillin in anti-gonorrhoea dosages. Acta Derm Venereol (Stockh) 1968;48:260-7.

3 Robertson DHH, McMillan A, Young H. Clinical practice in sexually transmissible diseases. 1st ed. Bath: Pitman Medical, 1980:94.

4 Lim KB, Thirumoorthy T, Lee CT, Sng EH, Tan T. Three regimens of procaine penicillin $\mathrm{G}$, Augmentin, and probenicid compared for treating acute gonorrhoea in men. Genitourin Med 1986;62:82-5. 